\title{
Surveillance of childhood blood lead levels in Chengdu, China in 2010-2011
}

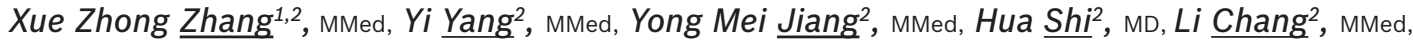 \\ Jia $\underline{L i}^{2}$, MMed, Hui Yang${ }^{2}$, MD
}

INTRODUCTION Lead poisoning has been receiving great attention around the world. The Child Hygiene Cooperation Center of the World Health Organization in China has been conducting investigations to monitor blood lead levels (BLLs) from as early as 2004. However, only several lead poisoning studies have been conducted in China since August 2009. The aim of the present study was to investigate the BLLs in children aged $<7$ years and to analyse the risk factors of high BLLs in Chengdu, China.

METHODS Questionnaires were distributed to children in Chengdu from 2010 to 2011. A total of 2,271 children were included in this study $-1,157$ received BLL tests in 2010 and the remaining received the tests in 2011. BLL was measured using a tungsten atomiser absorption spectrophotometer.

RESULTS The mean BLL of the 2,271 children was $6.2 \mu \mathrm{g} / \mathrm{dL}$ and $2.03 \%$ of the children had BLLs $\geq 10 \mu \mathrm{g} / \mathrm{dL}$. Mean BLL seemed to increase with age. Unhygienic habits (e.g. not washing hands frequently, biting of toys and pencils), history of pica, use of coal and residence in an industrial zone were found to be the main risk factors contributing to high BLL $(p<0.05)$. Children with high BLLs have a higher risk of manifesting anorexia and/or abdominal pain as compared to those with low BLLs $(p<0.05)$.

CONCLUSION The mean BLL of children in Chengdu (i.e. $6.2 \mu \mathrm{g} / \mathrm{dL}$ ) was found to be higher than that of children in developed countries. Childhood lead poisoning remains a public health problem.

Keywords: blood lead level, children, China, lead poisoning, risk factor

\section{INTRODUCTION}

Lead, a highly toxic metal, is commonly found in the environment due to human activities, such as mining, manufacturing and burning of fossil fuels. ${ }^{(1)}$ Lead is also widely used in a variety of products (e.g. lead car batteries, paints, water pipes, cosmetic products, hair dyes and building materials). ${ }^{(1,2)}$ Therefore, the effect of lead exposure is an important health issue. This is especially the case when children are concerned, as they are more likely to play in dirt and insert objects into their mouths, resulting in a higher risk of lead exposure as compared to adults. ${ }^{(3)}$ Many studies have revealed that elevated blood lead levels (BLLs), i.e. BLLs $\geq 10 \mu \mathrm{g} / \mathrm{dL}$, can result in adverse health effects including encephalopathy, cardiovascular disease, immune system disease and anaemia. ${ }^{(4-10}$ Lead primarily affects the central nervous system, particularly

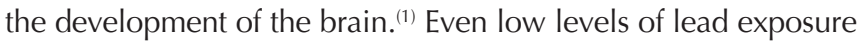
have been shown to be associated with impairment of children's cognitive function and abnormal infant behaviour. ${ }^{(11-13)}$

Since the last half of the 20th century, lead poisoning has been receiving serious attention in developed countries. ${ }^{(14)}$ Thereafter, regulatory and environmental reforms have occurred, which resulted in significant mitigation of elevated BLLs among children in developed countries. ${ }^{(15)}$ In recent years, lead exposure has received serious attention from Chinese scientists, and since 2004, the Child Hygiene Cooperation Center of the World Health Organization (WHO) in China has been carrying out investigations to monitor the BLLs of children from 14 Chinese cities.(16) One study conducted in China reported that lead poisoning has affected more than 4,000 children in several Chinese cities and that the BLLs of most of the affected children were $>25 \mu \mathrm{g} / \mathrm{dL} .{ }^{(17)}$ Such findings indicate that there is a need for large, population-based investigations to objectively assess BLLs and that practical guidelines for the prevention and treatment of childhood lead poisoning should be developed. Thus, the aim of the present study was to collect large amounts of data (i.e. BLLs and health points) on the children living in Chengdu, so as to examine the BLLs and analyse the risk factors and symptoms of lead poisoning.

\section{METHODS}

Children aged $<7$ years were eligible for inclusion in the study. Only the results of the first set of BLL tests were used, and the child's name and identification number as well as time of investigation were documented. Children with known severe diseases, such as acute abdomen caused by acute appendicitis, were excluded. The number of children included in the study in 2010 and 2011 were 1,157 and 1,135, respectively. As 21 children participated in both enrolments, the second set of data (i.e. the data taken in 2011) of these children was excluded from the analysis. In other words, all analyses were done based on data from 2,271 children.

Children aged 3 to $<7$ years were sampled from kindergartens during regular check-ups, while children aged $<3$ years were

${ }^{1}$ Department of Laboratory Medicine, Central Hospital of Zibo, Zibo, Shandong, ${ }^{2}$ Department of Laboratory Medicine, West China Second University Hospital, Sichuan University, Chengdu, Sichuan, China

Correspondence: Prof Hui Yang, Professor, Department of Laboratory Medicine, West China Second University Hospital, Sichuan University, Number 20, Section 3, Ren Min Nan Lu, Chengdu, Sichuan 610041, China. yanghui00@163.com 
sampled from community child health clinics during mandatory and periodic visits. Our study cohort included children from all 19 regions of Chengdu. The geographic distribution of the children is shown in Table I. As the analysis of BLLs was offered at no charge, most parents consented to their child's participation in the study. Fasting venous blood samples were collected from the children only after their parents had provided informed consent and answered the questionnaire that was administered. Blood sampling was done in the Department of Laboratory Medicine, West China Second University Hospital, Sichuan University, Chengdu, China. Information such as the child's inhabited environment, living habits and health status were gathered from the questionnaire. The child's health, as well as birth history, body weight, body height and BLL, was measured using a health questionnaire.

Venous blood specimens were collected in Vacutainer tubes (Becton Dickinson, Franklin Lakes, NJ, USA) containing heparin lithium, and BLL was analysed twice using a well-controlled BH2100 tungsten atomiser absorption spectrophotometer (Beijing Bohui Innovation Technology Co Ltd, Beijing, China) within an hour after sampling. The mean BLL of the two measurements was recorded. Seronorm ${ }^{\mathrm{TM}}$ Trace Elements Whole Blood (SERO, Billingstad, Norway) was used at the beginning and end of each day to ensure that the equipment was properly calibrated.

Data obtained from the questionnaires was inputted into an EpiData database (The EpiData Association, Odense, Denmark). In accordance with WHO guidelines, the present study defined elevated BLL as a BLL value $\geq 10 \mu \mathrm{g} / \mathrm{dL} .{ }^{(18,19)}$ Statistical analyses were conducted using the Statistical Package for the Social Sciences version 18.0 (SPSS Inc, Chicago, IL, USA). Variance analysis was used to examine the differences in BLLs between groups. Differences among the age, gender, nationality and housing environment of the children were evaluated in a pairwise method using $t$-tests. Logistic regression analysis was used to analyse the risk factors of high BLL. Chi-square test was used to assess the correlation between BLL and clinical symptoms. A p-value $<0.05$ was considered to be statistically significant.

\section{RESULTS}

The mean age of the 2,271 children was 4.55 years (Table II). Among them, 1,356 were male and 915 were female, and 2,187 were of Han ethnicity and 84 were of Tibetan ethnicity. Most $(n=1,497)$ of the children lived in urban areas; 774 children lived in suburban areas. The mean BLL of the children was 6.2 (range 1.0-64.2) $\mu \mathrm{g} / \mathrm{dL}$ and most $(\mathrm{n}=2,225)$ of the children had BLLs $<10 \mu \mathrm{g} / \mathrm{dL}$.

The mean BLLs of the children according to their age are presented in Table III. 2.03\% of the children had BLLs $\geq 10 \mu \mathrm{g} / \mathrm{dL}$. The percentages of children with BLLs $\geq 10 \mu \mathrm{g} / \mathrm{dL}$ in 2010 and 2011 were $1.56 \%$ and $2.51 \%$, respectively. We found that BLLs tended to increase with age (Fig. 1). There was no significant difference between the BLLs of the boys and those of the girls, according to the 2010 dataset (Table IV). However, evaluation of the 2011 dataset showed that the boys had significantly higher BLLs than the girls $(p<0.05)$. We found no significance difference between the BLLs of Han children and those of Tibetan children. While children
Table I. Geographic distribution of the children in the study ( $n=2,271$ ).

\begin{tabular}{|c|c|c|c|c|c|}
\hline \multirow[t]{3}{*}{ Region } & \multicolumn{4}{|c|}{ No. of children } & \multirow[t]{3}{*}{ Total } \\
\hline & \multicolumn{2}{|c|}{2010} & \multicolumn{2}{|c|}{2011} & \\
\hline & Urban & Suburban & Urban & Suburban & \\
\hline Jinjiang & 65 & 38 & 57 & 21 & 181 \\
\hline Qingyang & 49 & 23 & 58 & 13 & 143 \\
\hline Jinniu & 62 & 35 & 52 & 27 & 176 \\
\hline Wuhou & 83 & 44 & 96 & 49 & 272 \\
\hline Chenghua & 38 & 20 & 54 & 16 & 128 \\
\hline Longquan & 32 & 21 & 37 & 15 & 105 \\
\hline Qingbaijiang & 20 & 17 & 25 & 14 & 76 \\
\hline Xindu & 25 & 15 & 28 & 19 & 87 \\
\hline Wenjiang & 58 & 33 & 53 & 28 & 172 \\
\hline Jintang & 25 & 11 & 27 & 16 & 79 \\
\hline Shuangliu & 42 & 26 & 37 & 18 & 123 \\
\hline Pixian & 49 & 20 & 41 & 22 & 132 \\
\hline Dayi & 26 & 19 & 24 & 17 & 86 \\
\hline Pujiang & 37 & 14 & 25 & 20 & 96 \\
\hline Xinjin & 28 & 15 & 26 & 11 & 80 \\
\hline Dujiangyan & 43 & 27 & 38 & 18 & 126 \\
\hline Penzhou & 18 & 8 & 23 & 11 & 60 \\
\hline Qionglai & 25 & 11 & 27 & 15 & 78 \\
\hline Chongzhou & 21 & 14 & 23 & 13 & 71 \\
\hline Total & 746 & 411 & 751 & 363 & 2,271 \\
\hline
\end{tabular}

Table II. Characteristics of the children in the study $(n=2,271)$.

\begin{tabular}{|c|c|c|c|}
\hline \multirow[t]{2}{*}{ Variable } & \multicolumn{3}{|c|}{ No. of children } \\
\hline & 2010 & 2011 & Total \\
\hline Age* $^{*}(y r)$ & $4.59 \pm 1.87$ & $4.51 \pm 1.86$ & $4.55 \pm 1.86$ \\
\hline \multicolumn{4}{|l|}{ Gender } \\
\hline Male & 684 & 672 & 1,356 \\
\hline Female & 473 & 442 & 915 \\
\hline \multicolumn{4}{|l|}{ Ethnicity } \\
\hline Han & 1,114 & 1,073 & 2,187 \\
\hline Tibetan & 43 & 41 & 84 \\
\hline \multicolumn{4}{|c|}{ Housing environment } \\
\hline Urban & 746 & 751 & 1,497 \\
\hline Suburban & 411 & 363 & 774 \\
\hline$B L L^{+}(\mu g / d L)$ & $\begin{array}{c}6.5 \pm 3.4 \\
(1.9-56.5)\end{array}$ & $\begin{array}{c}6.0 \pm 3.5 \\
(1.0-64.2)\end{array}$ & $\begin{array}{c}6.2 \pm 3.5 \\
(1.0-64.2)\end{array}$ \\
\hline \multicolumn{4}{|l|}{ BLL ( $\mu \mathrm{g} / \mathrm{dL})$} \\
\hline $\mathrm{BLL}<10$ & 1,139 & 1,086 & 2,225 \\
\hline $10 \leq B L L<20$ & 12 & 22 & 34 \\
\hline $20 \leq \mathrm{BLL}<40$ & 2 & 3 & 5 \\
\hline $\mathrm{BLL} \geq 40$ & 4 & 3 & 7 \\
\hline
\end{tabular}

* Data presented as mean \pm standard deviation. †Data presented as mean \pm standard deviation (range). BLL: blood lead level

who lived in urban areas had higher BLLs than those who lived in suburban areas, this difference was also not significant.

Logistic regression analysis was performed to find factors that were significantly associated with high BLL (i.e. $\geq 10 \mu \mathrm{g} / \mathrm{dL}$ ). Confounders that were entered into the logistic regression analysis 
Table III. Mean blood lead levels (BLLs) and percentage of children $(n=2,271)$ with BLLs $\geq 10 \mu \mathrm{g} / \mathrm{dL}$, according to age.

\begin{tabular}{|c|c|c|c|c|c|c|}
\hline \multirow[t]{2}{*}{$\begin{array}{l}\text { Age } \\
\text { (yr) }\end{array}$} & \multicolumn{3}{|c|}{$\begin{array}{c}\text { Mean BLL } \pm \text { SD } \\
(\mu \mathrm{g} / \mathrm{dL})\end{array}$} & \multicolumn{3}{|c|}{$\begin{array}{c}\% \text { of children with } \\
\text { BLLs } \geq 10 \mu \mathrm{g} / \mathrm{dL}\end{array}$} \\
\hline & 2010 & 2011 & Total & 2010 & 2011 & Tota \\
\hline 0 & $5.1 \pm 1.6$ & $4.8 \pm 1.8$ & $4.9 \pm 1.7$ & 1.00 & 2.00 & 1.50 \\
\hline 1 & $5.8 \pm 2.5$ & $6.3 \pm 7.6$ & $6.1 \pm 5.8$ & 1.00 & 4.00 & 2.50 \\
\hline 2 & $6.3 \pm 4.8$ & $5.7 \pm 2.6$ & $6.0 \pm 3.8$ & 1.00 & 3.00 & 2.00 \\
\hline 3 & $6.6 \pm 5.1$ & $5.8 \pm 1.9$ & $6.2 \pm 3.8$ & 3.11 & 2.21 & 2.66 \\
\hline 4 & $6.6 \pm 2.2$ & $6.1 \pm 2.3$ & $6.4 \pm 2.3$ & 1.97 & 2.05 & 2.01 \\
\hline 5 & $6.7 \pm 1.5$ & $6.6 \pm 4.6$ & $6.6 \pm 3.4$ & 0.00 & 2.48 & 1.22 \\
\hline $6-7$ & $7.0 \pm 3.6$ & $6.1 \pm 2.2$ & $6.6 \pm 3.1$ & 1.80 & 2.62 & 2.18 \\
\hline Total & $6.5 \pm 3.4$ & $6.0 \pm 3.5$ & $6.2 \pm 3.5$ & 1.56 & 2.51 & 2.03 \\
\hline
\end{tabular}

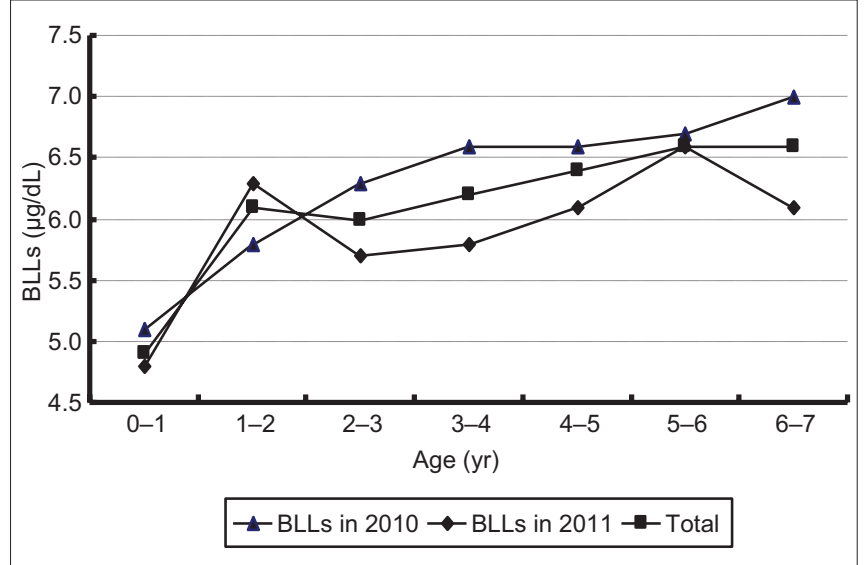

SD: standard deviation

Fig. 1 Graph shows the trend of blood lead levels (BLLs) by age.

Table IV. Mean blood lead levels (BLLs) of the children $(n=2,271)$ according to gender, ethnicity and housing environment.

\begin{tabular}{|c|c|c|c|c|c|c|}
\hline \multirow[t]{2}{*}{ Variable } & \multicolumn{2}{|c|}{2010} & \multicolumn{2}{|c|}{2011} & \multicolumn{2}{|c|}{ Total } \\
\hline & $\begin{array}{c}\text { Mean BLL } \pm \text { SD } \\
(\mu g / d L)\end{array}$ & p-value & $\begin{array}{c}\text { Mean BLL } \pm \text { SD } \\
(\mu \mathrm{g} / \mathrm{dL})\end{array}$ & p-value & $\begin{array}{c}\text { Mean BLL } \pm \text { SD } \\
(\mu \mathrm{g} / \mathrm{dL})\end{array}$ & p-value \\
\hline Male & $6.5 \pm 3.2$ & & $6.2 \pm 3.7$ & & $6.3 \pm 3.4$ & \\
\hline Female & $6.4 \pm 3.7$ & & $5.7 \pm 3.3$ & & $6.1 \pm 3.5$ & \\
\hline Han & $6.5 \pm 3.5$ & & $6.0 \pm 3.6$ & & $6.2 \pm 3.5$ & \\
\hline Tibetan & $6.1 \pm 1.6$ & & $5.9 \pm 2.7$ & & $6.1 \pm 2.2$ & \\
\hline Housing environment & & 0.252 & & 0.926 & & 0.427 \\
\hline Urban & $6.1 \pm 3.3$ & & $6.4 \pm 2.8$ & & $6.3 \pm 3.1$ & \\
\hline Suburban & $5.9 \pm 3.7$ & & $6.5 \pm 3.9$ & & $6.2 \pm 3.8$ & \\
\hline
\end{tabular}

SD: standard deviation

Table V. Risk factors found to be significantly associated with high blood lead level in logistic regression analysis.

\begin{tabular}{lcc}
\hline Risk factor & p-value & $\begin{array}{c}\text { Adjusted } \\
\text { OR }\end{array}$ \\
\hline Pica history & 0.040 & 3.607 \\
Infrequent hand-washing & 0.046 & 5.650 \\
Habit of sucking fingers & 0.041 & 2.569 \\
Habit of biting toys & 0.028 & 2.573 \\
Habit of biting pencils & 0.011 & 3.327 \\
Use of coal & 0.031 & 1.413 \\
Frequent consumption of Chinese & 0.047 & 2.060 \\
medical herbs & & 1.910 \\
Frequent consumption of puffed foods & 0.039 & 1.490 \\
Use of breast milk substitutes & 0.046 & 3.148 \\
Residence in industrial zone & 0.021 & \\
\hline
\end{tabular}

OR: odds ratio

included gender (male), ethnicity (Han), living in scattered housing, residing in a single-storey house, residing in a house beside the streets, use of lead fuel and pica history. Factors that were found to be significantly associated with high BLL (i.e. $p$ $<0.05$ ) and their adjusted odds ratios are listed in Table V. Risk factors that were found to be significantly associated with high BLL in children aged $<7$ are: (a) pica history; (b) infrequent hand-washing; (c) the habit of sucking fingers, biting toys or biting pencils; (d) the use of coal; (e) frequent consumption of
Table VI. Clinical correlates of blood lead levels (BLLs) of children $(n=2,271)$ aged $0-7$ years.

\begin{tabular}{lccrr}
\hline $\begin{array}{l}\text { Clinical } \\
\text { correlate }\end{array}$ & \multicolumn{2}{c}{ No. of children } & $\chi^{2}$ & p-value \\
\cline { 2 - 4 } & $\begin{array}{c}\mathbf{B L L} \geq \mathbf{1 0} \mathbf{\mu g} / \mathbf{d L} \\
(\mathbf{n}=\mathbf{4 6})\end{array}$ & $\begin{array}{c}\mathbf{B L L}<\mathbf{1 0} \mathbf{\mu g} / \mathbf{d L} \\
(\mathbf{n}=\mathbf{2 , 2 2 5})\end{array}$ & & \\
\hline Anorexia & 18 & 233 & 37.652 & $<0.001$ \\
$\begin{array}{l}\text { Abdominal } \\
\text { pain }\end{array}$ & 9 & 215 & 4.971 & 0.040 \\
$\begin{array}{l}\text { Constipation } \\
\text { Difficulty in }\end{array}$ & 7 & 461 & 0.834 & 0.361 \\
learning & 5 & 198 & 0.215 & 0.643 \\
\hline
\end{tabular}

Chinese medical herbs and puffed foods; ( $\mathrm{f}$ ) the use of breast milk substitutes; and (g) residence in an industrial zone.

The correlation between elevated BLL and clinical symptoms such as anorexia, abdominal pain (i.e. lead-induced colic, and not acute appendicitis, cholecystitis or other causes of acute abdomen), constipation and difficulty in learning were assessed. The results of this analysis are shown in Table VI. Anorexia and abdominal pain were found to be significantly related to elevated BLL $(p<0.05)$.

\section{DISCUSSION}

The mean BLL of the 2,271 children (aged $<7$ years) in the present study was $6.2 \mu \mathrm{g} / \mathrm{dL}$, and the prevalence of elevated 
BLL was found to be $2.03 \%$ for both years (2010 and 2011). We also observed that BLLs rose with increasing age. Several risk factors were identified to be associated with elevated BLL, including the use of coal, pica history, residence in an industrial zone, unhygienic habits (e.g. sucking fingers, not frequently washing hands, biting toys and biting pencils), the use of breast milk substitutes, and frequent consumption of Chinese medical herbs and puffed foods. The present study also showed that anorexia and abdominal pain were significantly associated with elevated BLL.

In the present study, the mean BLL of the children in 2010 and 2011 were $6.5 \mu \mathrm{g} / \mathrm{dL}$ and $6.0 \mu \mathrm{g} / \mathrm{dL}$, respectively. In a previous study, ${ }^{(20)}$ the mean BLL of children in Chengdu in 2007, 2008 and 2009 were found to be $6.6 \mu \mathrm{g} / \mathrm{dL}, 5.7 \mu \mathrm{g} / \mathrm{dL}$ and $6.4 \mu \mathrm{g} / \mathrm{dL}$, respectively. In other words, the BLLs of children in 2010-2011 are similar to those in 2007-2009. One study reported that there was no difference in the BLLs of children before and after the lead poisoning event in Longchang, which is situated not far from the city of Chengdu. ${ }^{(17)}$ As studies have shown that even 'low' BLLs (i.e. $>5 \mu \mathrm{g} / \mathrm{dL}$ ) may influence children's neurobehavioral performance, ${ }^{(1,21,22)}$ effective measures should be taken to reduce the BLLs of children.

In 1997, the United States Centers for Disease Control and Prevention divided the prevalence of elevated BLL into three categories: (a) higher than 12\%: high epidemic area; (b) 6\%-12\%: moderate epidemic area; and (c) lower than 5.9\%: low epidemic area. ${ }^{(20)}$ Based on this categorisation and the sharp decrease in the prevalence of elevated BLL (from 9.2\% ${ }^{(19)}$ to $2.03 \%$ since 2007) in Chengdu, Chengdu is now a low epidemic area. This sharp decrease in the presence of elevated BLL is likely due to the elimination of leaded gasoline, which has been implemented in China since July 1, 2000.

Although Chengdu currently belongs to the 'low epidemic area' category, the BLLs of the children in Chengdu are still relatively high; the mean BLL of the children in the present study was $>6 \mu \mathrm{g} / \mathrm{dL}$. Therefore, even though no lead poisoning event has been reported in Chengdu (unlike in Longchang, which has BLLs > $\left.25 \mu \mathrm{g} / \mathrm{dL}^{(17)}\right)$, BLL detection should still be carried out routinely to prevent high BLLs from causing unwanted damages.

The present study's finding that BLLs increase with age, from 0 to $<7$ years, is consistent with that of many studies. ${ }^{(23,24)}$ The evaluation of our 2011 dataset showed that BLLs were significantly higher in boys than in girls. This finding is consistent with that of Zhang et al's study, which involved 14 Chinese cities in 2004-2006. ${ }^{(16)}$ However, the 2007-2010 data from the present study and a previous study ${ }^{(20)}$ yielded different results; the data obtained during that period showed no significant difference in the BLLs of boys and girls. This may be due to population mobility or sampling error. There may also be regional differences in the BLLs of boys and girls. In the present study, we also found that the mean BLL of Tibetan children was slightly lower than that of the Han children in Chengdu, although this difference did not reach a significant level.

In the present study, we found that children with unhygienic habits (e.g. sucking fingers, not frequently washing hands, biting toys and biting pencils) were more likely to have elevated BLLs. This finding, although not observed in our previous study, ${ }^{(20)}$ is consistent with many other studies. ${ }^{(3,25-27)}$ Frequent consumption of Chinese medical herbs and puffed foods as well as the use of breast milk substitutes were found to be risk factors for elevated BLL in both our previous study ${ }^{(20)}$ and the present study.

Elevated BLL is a known multi-target toxicant, with effects on the haematopoietic, nervous, immune and gastrointestinal systems. ${ }^{(4-10)}$ Abdominal pain is frequently reported when BLL is $>40 \mu \mathrm{g} / \mathrm{dL}$. In the present study, anorexia and abdominal pain were found to be significantly associated with elevated BLL. While lead toxicity is an uncommon cause of acute abdominal pain, several cases of acute abdominal pain have been reported to be caused by lead toxicity. ${ }^{(28,29)}$ The diagnosis of lead toxicity is often delayed, as the abdominal pain is often mistaken to be caused by acute appendicitis, acute cholecystitis or other more common causes of acute abdomen. The monitoring of BLLs in children suffering from anorexia and/or abdominal pain may be useful in identifying children with elevated BLL.

The present study was not without limitations. First, we only evaluated and identified a small number of risk factors associated with elevated BLL. Second, the sample size was relatively small. To obtain more comprehensive and accurate findings, future studies should evaluate a greater number of risk factors and use a larger sample size.

In conclusion, the BLLs of children in Chengdu were found to be higher than those of children from other areas in China and developed countries. As lead poisoning in children is a public health problem in China, unhygienic habits in children and environmental pollution should be considered and addressed. In order to prevent lead poisoning, there needs to be greater collaboration among the government, the society and families.

\section{REFERENCES}

1. Agency for Toxic Substances and Disease Registry (ATSDR). Toxicological Profile for lead. Atlanta, GA, USA: US Department of Health and Human Services, Public Health Service, 2006, ATSDR [Online]. Available at: http:/ www.atsdr.cdc.gov. Accessed January 11, 2009.

2. National Institute of Environmental Health Services. Lead. USA: Research Triangle Park, NC; 2009 [Online]. Available at: http://www.niehs.nih.gov/ health/topics/agents/lead/index.cfm. Accessed January 22, 2009.

3. Sanders T, Liu Y, Buchner V, Tchounwou PB. Neurotoxic effects and biomarkers of lead exposure: a review. Rev Environ Health 2009; 24:15-45.

4. Weaver VM, Jaar BG, Schwartz BS, et al. Associations among lead dose biomarkers, uric acid, and renal function in Korean lead workers. Environ Health Perspect 2005; 113:36-42.

5. Kuo HW, Hsiao TY, Lai JS. Immunological effects of long-term lead exposure among Taiwanese workers. Arch Toxicol 2001; 75:569-73.

6. Al-Neamy FR, Almehidi AM, Alwash R, et al. Occupational lead exposure and amino acid profiles and liver function tests in industrial workers. Int J Environ Health Res 2001; 11:181-8.

7. Bonde JP, Joffe M, Apostoli P, et al. Sperm count and chromatin structure in men exposed to inorganic lead: lowest adverse effect levels. Occup Environ Med 2002; 59:234-42.

8. Lanphear BP, Hornung R, Khoury J, et al. Low-level environmental lead exposure and children's intellectual function: an international pooled analysis. Environ Health Perspect 2005; 113:894-9.

9. Martin D, Glass TA, Bandeen-Roche K, et al. Association of blood lead and tibia lead with blood pressure and hypertension in a community sample of older adults. Am J Epidemiol 2006; 163:467-78.

10. Lustberg M, Silbergeld E. Blood lead levels and mortality. Arch Intern Med 2002; 162:2443-9.

11. Koller K, Brown T, Spurgeon A, Levy L. Recent developments in low-level 
lead exposure and intellectual impairment in children. Environ Health Perspect 2004; 112:987-94.

12. Centers for Disease Control and Prevention (CDC) Advisory Committee on Childhood Lead Poisoning Prevention. Interpreting and managing blood lead levels $<10$ microg/dL in children and reducing childhood exposures to lead: recommendations of CDC's Advisory Committee on Childhood Lead Poisoning Prevention. MMWR Recomm Rep 2007; 56(RR-8):1-16.

13. Canfield RL, Henderson CR Jr, Cory-Slechta DA, et al. Intellectual impairment in children with blood lead concentrations below 10 microg per deciliter. N Engl J Med 2003; 348:1517-26.

14. Meyer PA, Pivetz T, Dignam TA, et al; Centers for Disease Control and Prevention. Surveillance for elevated blood lead levels among children-United States, 1997-2001. MMWR Surveill Summ 2003; 52:1-21.

15. Riddell TJ, Solon O, Quimbo SA, et al. Elevated blood-lead levels among children living in the rural Philippines. Bull World Health Organ 2007; 85:674-80.

16. Zhang SM, Dai YH, Xie XH, et al. Surveillance of childhood blood lead levels in 14 cities of China in 2004-2006. Biomed Environ Sci 2009; 22:288-96.

17. Ji A, Wang F, Luo W, et al. Lead poisoning in China: a nightmare from industrialisation. Lancet 2011; 377:1474-6.

18. US Centers for Disease Control. Preventing lead poisoning in young children. US Centers for Disease Control, Atlanta. 1991

19. International Programme on Chemical Safety (IPCS). Inorganic lead Environmental Health Criteria 165. Geneva: WHO; 1995.

20. Shi H, Jiang YM, Li JY, et al. Environmental lead exposure among children in Chengdu, China, 2007-2009. Biol Trace Elem Res 2011; 143:97-102.

21. Min JY, Min KB, Cho SI, et al. Neurobehavioral function in children with low blood lead concentrations. Neurotoxicology 2007; 28:421-5.

22. Agency for Toxic Substances and Disease Registry (ATSDR). Hazardous Substance Release and Health Effects Database (HazDat). Atlanta, GA: Centers for Disease Control and Prevention; 2006. Available at: http:// www.atsdr.cdc.gov/hazdat.html. Accessed January 11, 2009.

23. Bernard SM, McGeehin MA. Prevalence of blood lead levels >or= 5 micro g/dL among US children 1 to 5 years of age and socioeconomic and demographic factors associated with blood of lead levels 5 to 10 micro g/dL, Third National Health and Nutrition Examination Survey, 1988-1994. Pediatrics 2003; 112:1308-13.

24. Wang S, Zhang J. Blood lead levels in children, China. Environ Res 2006; 101:412-8.

25. Advisory Committee on Childhood Lead Poisoning Prevention (ACCLPP). Recommendations for blood lead screening of young children enrolled in medicaid: targeting a group at high risk. MMWR Recomm Rep 2000; 49(RR-14):1-13.

26. Freeman NC, Jimenez M, Reed KJ, et al. Quantitative analysis of children's microactivity patterns: The Minnesota Children's Pesticide Exposure Study. J Expo Anal Environ Epidemiol 2001; 11:501-9.

27. Ko S, Schaefer PD, Vicario CM, Binns HJ; Safer Yards Project. Relationships of video assessments of touching and mouthing behaviors during outdoor play in urban residential yards to parental perceptions of child behaviors and blood lead levels. J Expo Sci Environ Epidemiol 2007; 17:47-57.

28. Masoodi M, Zali MR, Ehsani-Ardakani MJ, et al. Abdominal pain due to lead-contaminated opium: a new source of inorganic lead poisoning in Iran. Arch Iran Med 2006; 9:72-5.

29. Shiri R, Ansari M, Ranta M, Falah-Hassani K. Lead poisoning and recurrent abdominal pain. Ind Health 2007; 45:494-6. 